\title{
Application of Trend Analysis Method for Emergency Planningin NPP Accident
}

\section{Pande M.U., Kuntjoro S.}

Center for Reactor Technology and Nuclear Safety National Nuclear Energy Agency-BATAN, Puspiptek-Complex OB. 80, Serpong 15310, Indonesia

\section{Abstract}

A decision for emergency response should be taken based on existing nuclear preparedness assessment. However, lessons learned from the Fukushima accident revealed that emergency response personals had difficulties in estimating time duration needed for the emergency actions. For that case, it is needed an alternative way to determine the time required for a response to be implemented. The objective of this paper is to applicate the trend analysis method for an emergency planning in NPP accident, especially to estimate time duration of countermeasures such as sheltering, evacuation, and relocation. Estimation was done based on consequences and dose data of PWR-1000 MWe severe accident which was simulated for West Bangka site. Dose and consequence estimations were calculated using Pc-cosyma software, and trend analysis application was performed

Corresponding Author: Pande M.U., Kuntjoro S., email: pmade-u@batan.go.id

Received: 29 July 2016 Accepted: 21 August 2016 Published: 21 September 2016

\section{Publishing services} provided by Knowledge E

Pande M.U., Kuntjoro S. This article is distributed under the terms of the Creative Commons Attribution License, which permits unrestricted use and redistribution provided that the original author and source are credited.

Selection and Peer-review under the responsibility of the ICONETS Conference Committee.

\section{G OPEN ACCESS} using statistical software. The result of simulation are: iodine tablets are to be distributed to residents in the area within radius of $20-30 \mathrm{~km}$; sheltering countermeasure is needed within the radius of $20-30 \mathrm{~km}$ for 12 weeks; evacuation is subjected for the area of $20 \mathrm{~km}$ from reactor for duration of 12 weeks; relocation is subjected to radius of $10 \mathrm{~km}$ for 2.5 years. The trend analysis can be used for supporting the decision making, especially for emergency planning. The advantage of this method is that it can provide quicker result than past methods. Besides, uncertainties can be reduced by using accurate input data and selection of suitable computation model.

Keywords: trend analysis, emergency response, NPP, accident

\section{Introduction}

The Fukushima accident, which was classified as severe accident, has caused great impacts and health consequences to people who live in the vicinity of the site [1-4]. In the early stage of the accident, the operator could not determine the severity of the impact. Emergency decision for countermeasure was taken based on emergency preparedness assessment [5-6]. However, by using existing emergency preparedness, it was difficult to estimatetime duration for each countermeasure. An assessment of accident impact is necessary in order to know the severity of the consequences and to determine the actions needed. The actions of countermeasure can be divided into two types i.e. short-term countermeasures such as providing iodine tablet, sheltering and evacuation, and long-term countermeasures which include population relocation. Time duration of countermeasure is estimated based on the radiation exposure, doses, and risk assessment [7], while the in situ real time measurement 
is needed to complement the estimation. By using real time doses, it is difficult to estimate time duration of countermeasure planning, such as time duration for sheltering, evacuation, and relocation. However using simulation data is also difficult because of the presence of simulation uncertainty $[8,9]$.

Therefore, an alternative way is needed to estimate the time required for countermeasures. In statistical method, trend analysis is could be used to interpret uncertain events in the past, and to predict future events. Trend estimation is a statistical technique to aid data interpretation. When a series of measurements of a process are treated as a time series, trend estimation can be used to make and justify statements about tendencies in the data, by relating the measurements to the times at which they occur. By using trend estimation, statements about tendencies in the data can be made and justified. The objective of this paper is to applicate of trend analysis method for emergency planning in NPP accident, especially to estimate the time duration of countermeasure such as sheltering, evacuation, and relocation. Estimation was done based on consequences and dose data of PWR-1000 MWe severe accident which was simulated for West Bangka site. Dose and consequence estimations were done by using Pccosyma software and trend analysis application was conducted using statistical software [10].

\section{Trend Analysis Methods and Applications}

Trend Analysis is: the practice of collecting information and attempting to spot a pattern, or trend, in the information; taking past data and using it to project future results, to project how the data might appear in the future [11]. Trend analysis is could be used to estimate uncertain events in the past, in statistics, trend analysis often refers to techniques for extracting an underlying pattern of behavior in a time series, which would otherwise be partly or nearly completely hidden by noise. Although trend analysis is often used to predict future events, it could be used to estimate uncertain events in the past.

Trend estimation is a statistical technique to aid interpretation of data. When a series of measurements of a process are treated as a time series, trend estimation can be used to make and justify statements about tendencies in the data, by relating the measurements to the times at which they occurred. By using trend estimation it is possible to construct a model which is independent of anything known about the nature of the process of an incompletely understood system (for example, physical, economic, or other system). This model can then be used to describe the behavior of the observed data. In particular, it may be useful to determine if measurements exhibit an increasing or decreasing trend which is statistically distinguished from random behavior. If we are missing data for a given period of time, you can interpolate a reasonable estimate based on the figures you do have.

Regression analysis is a statistical process for estimating the relationships among variables. It includes many techniques for modeling and analyzing several variables, when the focus is on the relationship between a dependent variable and one or more independent variables. Regression analysis is widely used for prediction and forecasting, where its use has substantial overlap with the field of machine learning. Regression analysis is also used to understand which among the independent variables are related to the dependent variable, and to explore the forms of these relationships. In restricted circumstances, regression analysis can be used to infer causal relationships between the independent and dependent variables. However this can lead to illusions or false relationships, so caution is advisable; for example, correlation does not imply causation. In statistics, linear regression is an approach for modeling the relationship between a scalar dependent variable $y$ and one or more explanatory variables denoted $X$. The 
R-squared value indicates how closely your trend line follows your data; the closer its value is to 1 , the closer it follows your data. This model can then be used to describe the behavior of the observed data.

A linear regression model assumes that the relationship between the dependent variable $y_{i}$ and the $p$-vector of regressors $x_{i}$ is linear. This relationship is modelled through a disturbance term or error variable $\varepsilon_{i}$ - an unobserved random variable that adds noise to the linear relationship between the dependent variable and regressors. Thus the model takes the form [11]:

$$
y_{i}=\beta_{1} x_{i 1}+\ldots \ldots+\beta_{p} x_{i p}+\varepsilon_{i}=\mathbf{X}_{i}^{1} \boldsymbol{\beta}+\varepsilon_{i}, \ldots \ldots \ldots \ldots \ldots . . i=1, \ldots \ldots \ldots,
$$

- $Y i$ is called the regress and, endogenous variable, response variable, measured variable, or dependent variable.

- Xi1, Xi2,....Xipare called regressors, exogenous variables, explanatory variables, covariates, input variables, predictor variables, or independent variables.

- The corresponding element of $\beta$ is called the intercept.

- Sometimes one of the regressors can be a non-linear function of another regressor or of the data, as in polynomial regression and segmented regression. The model remains linear as long as it is linear in the parameter vector $\beta$.

\section{Methodology}

The assessment consists of several calculations, that are core inventory calculation (PWR 1000 MWe), source term calculation of severe accident, consequences calculation (individual dose), countermeasures, andrisks. For estimation of countermeasure time duration use by trend analysis method.

Figure 1 shows flow chart of countermeasure assessment and estimation of countermeasure time duration. PC-COSYMA is a dose consequence and countermeasure assessment computer code according to segmented Gaussian diffusion model using source data derived from accident scenarios. Statitistical computer code for trend analysis of time duration countermeasure. Estimation and simulation on West Bangka site.

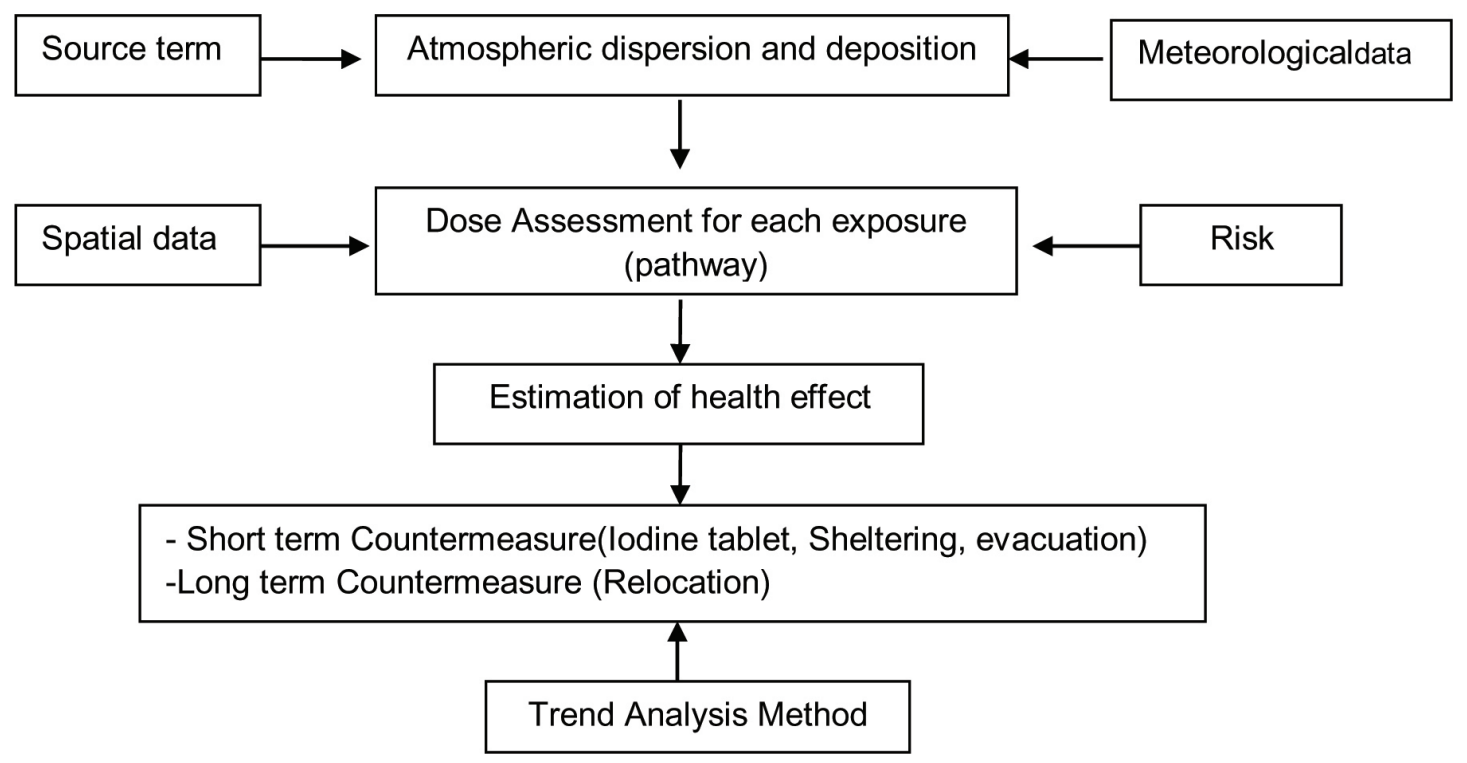

Figure 1: The assessment modelling for emergency planning. 


\section{Result and Discussion}

\section{Dose and Risk Calculation}

Figure 2 explain the individual effective dose received as a impact of PWR 1000 MWe accident at the site of West Bangka. In Fig. 2 describe that the individual dose decreases with increasing distance. The series of dose data in Figure 2 can be used to estimate the emergency planning. The statistical relationship between the individual doses and distance approximated by the equation range of exponential trend line model. Exponential trend line used to data that rises or falls at rates that increase constantly. Use an exponential trend line for data that rises or falls at rates that increase constantly.

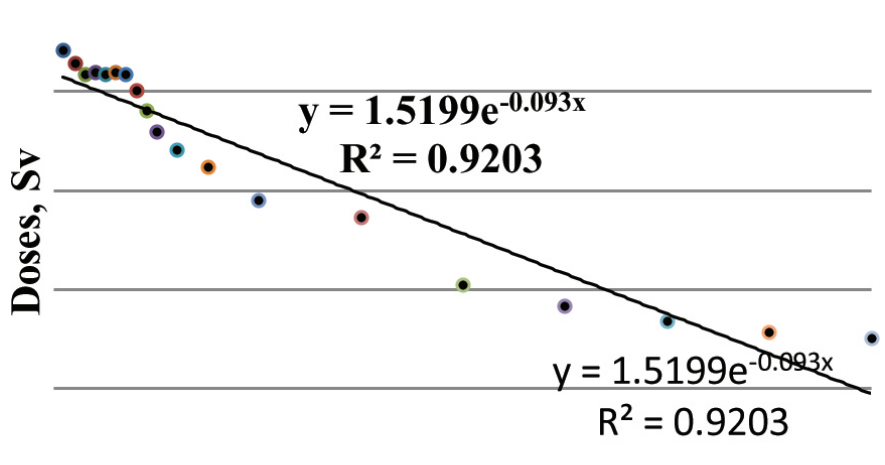

\section{Distance (km)}

Figure 2: Individual effective dose versus distance.

This trend line can be used with such things as radioactive decay, which progressively slows down over time. This trend line represents a steady rate of increase or decrease. Trend line follow the exponential equations:

$$
y=1.519\left(e^{-0.09 x}\right), R^{2}=0.920
$$

With $\mathrm{y}=$ individual dose and $\mathrm{x}$ = distance. The R-squared value indicates how closely your trend line follows your data; the closer its value is to 1 , the closer it follows your data. With the high R-squared value indicates this model can be applied to this data set on Fig.2 and eq. (2).

According to the basic policy in the ICRP-103 recommendation [11, 12], in the emergency activities such as nuclear accident the annual dose to the people is allowed up to $100 \mathrm{mSv}$. It's defined as emergency exposure situation. Post emergency situation, the annual dose is limited within $20 \mathrm{mSv}$ for the existing exposure situation for long-term exposure. Determination of counter measures are required to mitigate radiation exposure and health risks from radiation accident. Based on data in Fig. 2 and eq. (2), the countermeasure of severe accident at West Bangka was estimated. The countermeasure divided two classification are: short term (sheltering, evacuation, iodine distribution) and long term countermeasure (relocation) According to the criteria mentioned by the ICRP-63 [13], evacuation is recommended whenever the effective dose exceeds $50 \mathrm{mSv}$, and distribution lodine tablet when the effective dose exceeds $10 \mathrm{mSv}$.The zone for sheltering is recommended when the effective dose exceeds 10 $\mathrm{mSv}$, and relocation when the effective dose exceeds $100 \mathrm{mSv}$. 
The result of assessment in Fig. 2 and eq. (2) are:

- Relocation recommended at distance below $10 \mathrm{~km}$

- Evacuation recommended at distance $10-20 \mathrm{~km}$

- Sheltering recommended at distance $20-30 \mathrm{~km}$.

- Distribution of lodine tablet at distance $20-30 \mathrm{~km}$

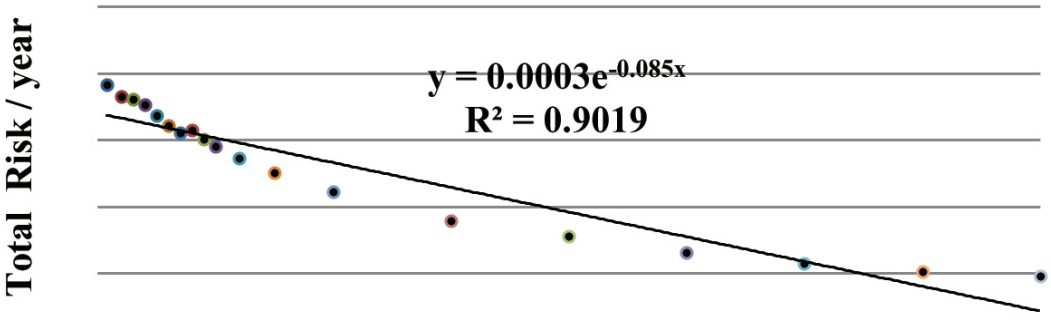

Distance, $\mathrm{km}$

Figure 3: Total risk versus distance.

Figure 3 described the total risk will be received as a impact of PWR 1000 MWe accident at the site of West Bangka. The radiological risk will diminish with increasing distance from reactor. Total risk decreased with increased distance. Trend line follow the exponential equations:

$$
y=0.001 e^{-0.08 x}, R^{2}=0.901
$$

When $y=$ total risk and $x=$ distance, high $R$-squared value indicates this model can be applied to this data set. (Fig. 3 and eq. (3)).

\section{Countermeasure}

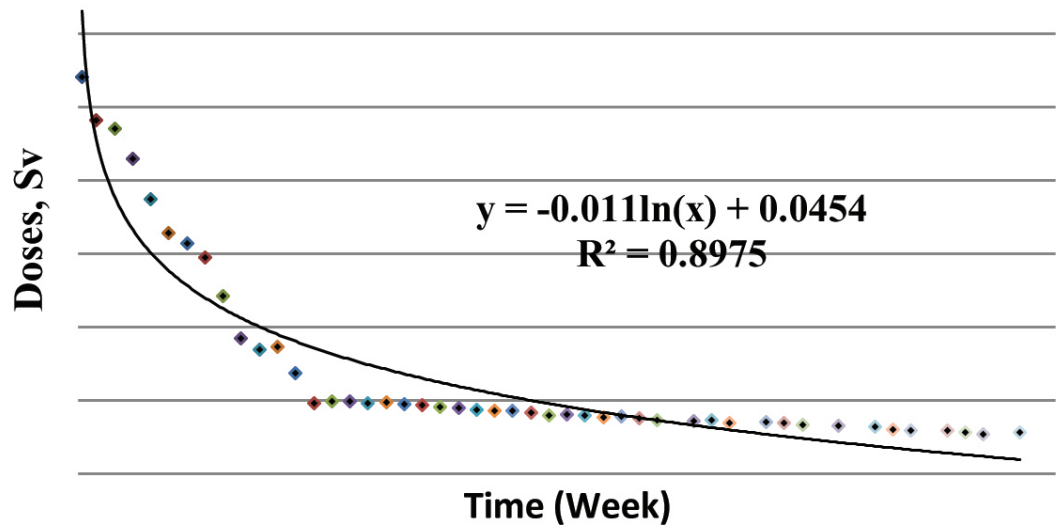

Figure 4: Effective intervention dose with time for sheltering at distance $30 \mathrm{~km}$.

Figure 4 show the effective intervention dose versus time for sheltering, the effective intervention dose decreases with increasing time of sheltering. The statistical relationship between the effective intervention dose and time for sheltering approximated by the equation range of logarithmic trend line. Trend line follow logarithmic equations: 


$$
y=-0.01 \ln (x)+0,897, R^{2}=0.897
$$

Where $y=$ effective intervention dose and $x=$ time for sheltering. High R-squared value indicates this model can be applied to this data set for Fig. 4 and eq. 4. By using trend analysis and trend estimation, it can be seen how long the action performed on residents sheltering in a radius of 20-30 km (based on Fig. 2 and eq. (2), If individual effective doses for sheltering is not exceeds $10 \mathrm{mSv}$ [13]. By drawing the time of Fig.2, the required to achieve a dose of 10 $\mathrm{mSv}$ for sheltering is 12 weeks. By using the correlation equation (4), obtained sheltering time is $10-12$ weeks.

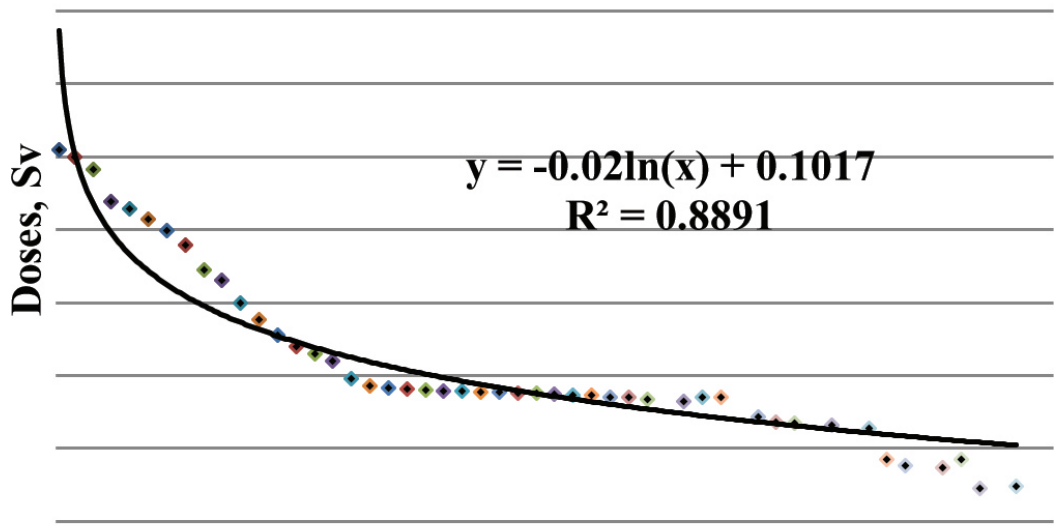

Time (Week)

Figure 5: Effective intervention dose with time for evacuation at distance $20 \mathrm{~km}$.

Figure 5 described of the relation effective intervention dose with evacuation time at distance $20 \mathrm{~km}$ when individual effective doses for sheltering is not exceeds $50 \mathrm{mSv}$. Fig. 5 show that the effective intervention dose decreases with increasing time of evacuation. The statistical relationship between the effective intervention dose and time for sheltering approximated by the equation range of logarithmic trend line. Trend line follow logarithmic equations:

$$
y=-0.02 \ln (x)+0.101, R^{2}=0.897
$$

Where $y=$ effective intervention dose and $x=$ time duration for evacuation. High R-squared value on Fig. 5 and eq. (5) indicates this model can be applied to this data set. By using trend analysis and trend estimation, it can be seen how long the action performed on residents evacuation in a radius of $20 \mathrm{~km}$. By drawing time on Fig. 5 required to achieve when the effective dose of evacuation isexceeds $50 \mathrm{mSv}$ for 11 weeks time duration. By using the correlation on equation (5), the obtained evacuation time is 12 weeks.

Figure 6. showed the Thyroid intervention dose $(\mathrm{IH})$ determining to iodine distribution. Distribution of iodine tablets do if acceptance effective dose of public at $50 \mathrm{mSv}$ From Figure 6 , distribution of lodine tablet at distance $20-30 \mathrm{~km}$. Iodine distribution decreases when the distance from NPP increases. Trend linein Fig. 6 is follow the exponential equations:

$$
y=5.737\left(x^{-1.81}\right) \text {, with } R^{2}=0.979
$$




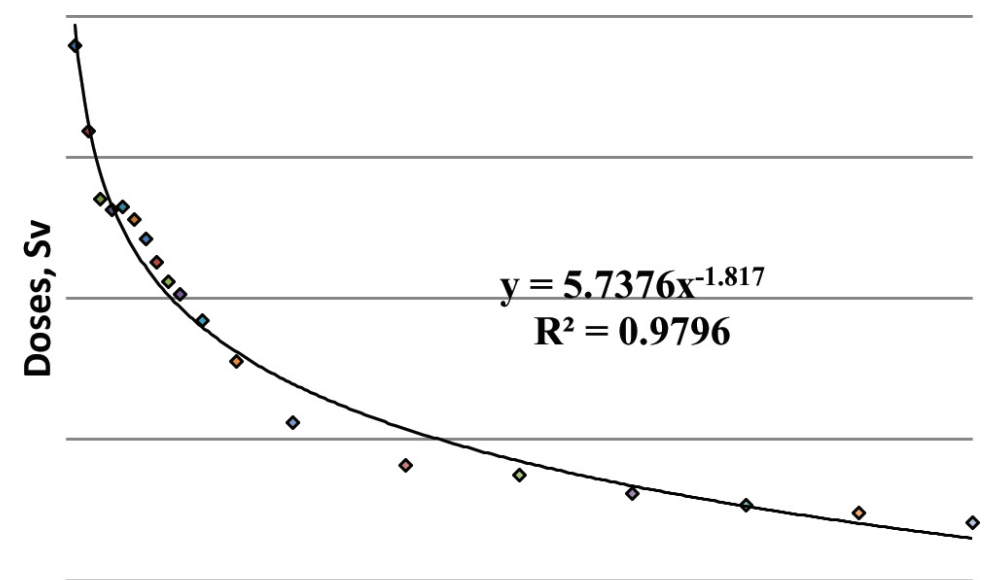

Distance (km)

Figure 6: Thyroid intervention dose (IH) for determining lodine distribution.

Where $\mathrm{y}=$ Thyroid intervention dose $(\mathrm{IH})$ for determining lodine distribution and $\mathrm{x}=$ distance. High R-squared value indicates this model can be applied to this data set. (Fig. 6 and eq. (6)).

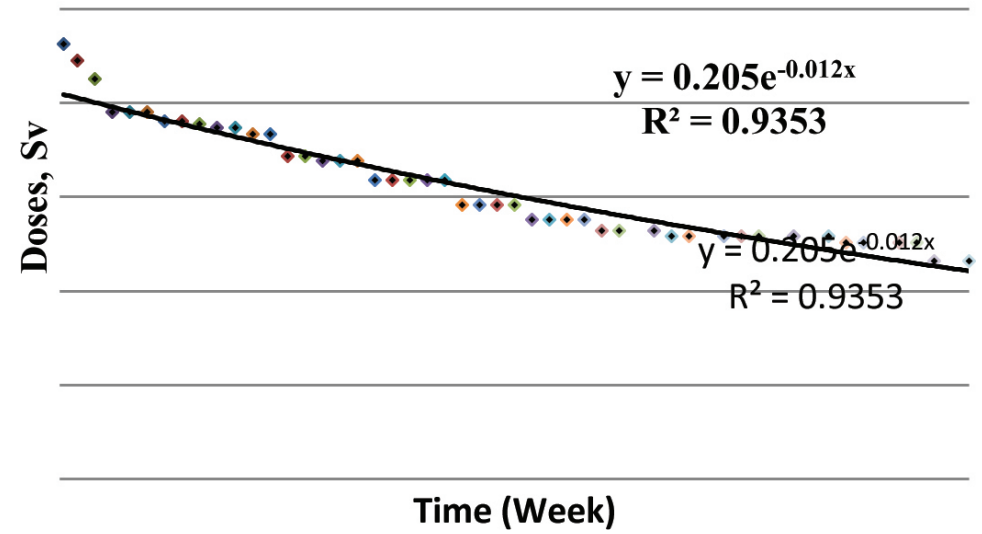

Figure 7: Effective intervention dose with time for relocation at distance $10 \mathrm{~km}$.

Figure 7 explain to relation of effective intervention dose versus time duration for relocation at distance $10 \mathrm{~km}$. Trend line in Fig. 7 is follow the exponential equations:

$$
y=0.205\left(e^{-0.01 x}\right) \text {, with } R^{2}=0.935
$$

Where $y=$ effective intervention dose and $\mathrm{x}=$ time duration for relocation. By using trend analysis and trend estimation, it can be seen how long the action performed on public relocation in a radius of $10 \mathrm{~km}$. By drawing time required to achieve when the effective dose exceeds $100 \mathrm{mSv}$, need the extrapolation mode. By using the correlation on equation (7) the obtained relocation time is 2.5 years.

\section{Conclusion}

The application of trend analysis method for emergency planning on PWR-1000 MWe accident at West Bangka has been resulted those are: iodine tablet are distributed to residents in the 
area within radius 20 - $30 \mathrm{~km}$; sheltering countermeasure is within the radius of $20-30 \mathrm{~km}$ for 12 weeks; evacuation is subjected for the area $20 \mathrm{~km}$ from reactor for evacuation time is 12 weeks; relocating is subjected to radius of $10 \mathrm{~km}$ for 2.5 years

Trend analysis can be used help for decision making, especially for the emergency planning, with the advantage in the use of trend analysis method, is faster than previous methods. Uncertainty can be reduced with accurate input data, and the selection of a suitable computation model.

\section{References}

[1] Tanaka S., "Accident at the Fukushima Dai-ichi nuclear power stations of TEPCO outline and lessons learned", Proc. Japan Acad. Ser. B 88, pp. 471-473, (2012)

[2] Nagataki S, Takamura N., Kamiya K. and Akashi M., "Measurements of individual radiation doses in residents living around the Fukushima nuclear power plant", Radiat. Res. 180, pp. 439-47, (2013)

[3] Gilberto Espinosa-Paredes G. E., "Severe Accident Analysis in Nuclear Power Plants", Science and Technology of Nuclear Installations, Volume 1, Article ID 430471, PP 1-2, doi:10.1155/2012/430471, (2012)

[4] Gonzalez A. J, et al, "Radiological protection issues arising during and after the Fukushima nuclear reactor accident", J. Radiol. Prot. Vol. 33, pp. 497-571, (2013)

[5] Pande M. U., Kuntjoro S., "Penentuan Zona Kedaruratan Nuklir Off-Site (Luar Tapak) di Indonesia", Journal of Waste Management Technology, ISSN 1410-9565, Akreditasi No. 399/ AU2/P2MI-LIPI/04/2012, Vol. 7 (2), pp. 58-65, (2014)

[6] Pande M. U., Kuntjoro S., "PSA Level 3 dan Implementasinya pada Kajian Keselamatan PWR", J. Tek. Reaktor. Nukl. Vol. 16 (1), ISSN 1411-240X, No. 402/AU2/P2MI-LIPI/04/2012, pp. 31-43, (2014)

[7] Puncher, M., "An assessment of the reliability of dose coefficients for intakes of radionuclides by members of the public", J. Radiol. Prot., Vol. 34, pp. 625-643, doi:10.1088 /0952-4746/33/3/573, (2014)

[8] Preston R. J. et al., "Uncertainties in estimating health risks associated with exposure to ionising radiation", J. Radiol. Prot., Vol .33. pp. 573-588, doi:10.1088 /0952-4746/33/3/573, (2013)

[9] Boice J. D., "Uncertainties in studies of low statistical power ", J. Radiol. Prot. Vol 30, PP 115-20, doi:10.1088, /0952-4746/33/3/573, (2010)

[10] Shumway R. H., Stoffer, Time Series Analysis and its Applications, Springer Springer, ISBNo-387-00857-8, (2011)

[11] ICRP-103, "Recommendation of the ICRP", ICRP-103-ICRP Publication, (2007),

[12] Shaw P., and Croüail, P., "ALARA in Existing Exposure Situations", J. Radiol. Prot., Vol. 33, PP. 487-490, doi:10.1088 /0952-4746/33/3/573, (2013)

[13] ICRP-63, Principle for Intervention for protection of the public in a Radiological Emergency, ICRP-63-ICRP Publication, (1992). 